\title{
Graduation Project and Learning Ability Cultivation of Undergraduates-examples of Inorganic Nonmetallic Materials Major
}

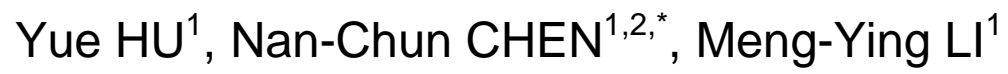 \\ ${ }^{1}$ College of Materials Science and Engineering, GuiLin University of TechnoAogy, Guilin, Guangxi \\ 541004 \\ ${ }^{2}$ Ministry of Education Key Aboratory of Nonferrous Materias and Advanced Processing \\ Technology,Guilin, Guangxi 541004
}

Key words: Undergraduates, Design of graduation thesis, Ability, Cultivation.

\begin{abstract}
According to the tracking investigation on topic selection of graduation project, practice process and oral defense situations of students in recent years, we find that there is a lack of thought and concept in the graduation project. Beneficial analysis and discusses on how to develop the function of teachers in graduation project, improve the initiative and positivity of students, develop the inner potential of students and help students achieve their own value have been carried out through analyzing the practical situations. Further more, suggestions which focus on topic selection of graduation project, design process as well as oral defense and evaluation have been proposed from ideal and conceptual aspects.
\end{abstract}

\section{Introduction}

Undergraduates should have the ability of thinking and judging independently, observing incisively and have plural mind, agility, global awareness and highly professional manners. The property and function of contemporary universities are required to be educational, academic, comprehensive, creative, social, service, industrial, autonomous, exploratory and international. The standard of cultivating qualified students of college is not judged by how many students the college has or how many students have got jobs when they graduate, but judged by the achievements and fortune they have contributed to the society. Every stage of the undergraduate college education is just like a product line. It should focus on the cultivation on comprehensive knowledge and various abilities. Graduation project is an end and conclusion of the four-year undergraduate college education and is also an important part of developing students' creative ability and improving their comprehensive quality. It is a procedure that we can check if students can analyze and solve practical problems by using theoretical knowledge that they have learned at school. As a result, students' work ability, attitude, creativity and their ability to utilize knowledge will be trained and enhanced.

\section{The main problems in graduation project of undergraduates}

According to the investigation on graduation project procedure in recent 3 years, it shows out that the process and details didn't reach the ideal effect. Satisfaction of topic selection method is $46 \%$, of selection content is $37 \%$. Match degree of topic selection and employment is only $16 \%$. In terms of the topic selection method, it is hoped to have a $97 \%$ match with employment, and $93 \%$ is selected through the cooperation with teachers. The result from blindly selecting topic is that $67 \%$ of the students are not interested in completing the project and know little about the topic contents, $69 \%$ of the students complete the paper unsatisfactorily, $57 \%$ of the students coordinate with teachers hard and $93 \%$ of the students accomplish difficultly. From the investigation results we can conclude that, first, the process of selecting design topic is blind, and teachers are not initiative enough, students can't work continuously as well. Second, students choose their teachers blindly and teachers just offer the topic of thesis to students, leaving them to fill the vacancy. What's more, students are lack of interaction with teachers and are difficult to accomplish the design because they are not familiar to the design 
requirements and process. And it is also hard to promote the activity and creativity of students. Third, students do the job just for graduation. Because of the lack of motive, the thesis is just word and oral defense is just a process for recent students.

For engineering major, the key of many engineering and craft research is design, and the key to design is innovation. It needs to be innovative and imaginative. At the past, graduation just focuses on the engineering design and graduation project. But from now on, it mainly focuses on the graduation thesis, which is similar and repeated in contents mostly. During the procedure of college graduation practice, students are acted as the tool of the teacher and they won't think independently and communicate with their teachers. They don't understand the whole concept and contents of the design and haven't experience the comprehensive design procedure. The feedback information indicates that student who can work independently during the design process, accomplish the experiments, analyze the data and settle the procedure can adjust the working surroundings and accomplish the work better.

\section{Graduation project and ability cultivation of students}

\section{Focus on the guidance on selecting topic and cultivate the knowledge re-creative ability of students}

Topic is selected on the basis of scientific practical produce and cultivation on comprehensive ability and innovative quality of students. It not only needs to consider the motive, work capacity, knowledge range and difficulty and whether it fits the basis requirements of the education, but also needs to combine with scientific produce as possible.

In order to arouse students' potential, we can adopt the bidirectional selection method. Teachers are required to take part in it. Students should have a better understanding on the details of graduation project, including the requirements of the topic, contents, experimental procedure and the expected results. And through the communication between teachers and students, they must focus on discovering the truth instead of just discussing to confirm a theme. Teachers should figure out students' motivation, work direction and creative thought and then help them know about the problems that will occur during the procedure later.

The label of the teachers is to transmit wisdom, impart knowledge and solve doubts. It is not true actually. In the age of technology and economy, we have extensive approaches to get knowledge. Students have the ability to analyze questions and operate practice skills through learning for years, including the professional knowledge they got from college. But they need guidance from the teachers on how to utilize this knowledge. Therefore, teachers are playing a quite important role here. Teachers must offer an environment and stimulate students' exploratory and curiosity and offer more academic exchange chances to students. As a result, the creativity and potential ability inside the students could be discovered and used. The interaction on academy and thought can promote students to develop freely and create a broader stage and better resources, and provide more communication chances for students. If the project is benefit for students' works in the future is also should be considered. On the other side, students should choose proper teachers according to the situations of themselves. It can not only mobilize the positivity of the students and help to find out the point where students are interested in, but also can improve the interaction between teachers and students.

\section{Guidance during the graduation project}

Examine the materials. The procedure of the graduation project is not a mission that just needs to complete a paper or translate a foreign document with thousands of words. It is a systematic project which needs the help and guidance from teachers and needs students to put themselves in it. During the materials collection period, teachers should make students clear about what they are going to do, and let them know about the relevant information about the project. And then lead students to definite the difficulty and emphasis of the project as well as the relevant knowledge areas. During this procedure, students should learn how to assemble scattered information into useful knowledge chains and then be used by themselves. 
Perfect the process and condition and cultivate students' innovative ability. On the basis of analyzing relevant materials and information, teachers need to design the craft route and parameter together with students and help them make clear why it is performed in this way. Wordage, numbers, formula and diagram must be used to describe and express the experimental process and method. Engineering design and data determination are not on the basis of imagination. It must be performed on experimental foundation before it is confirmed, combining with pervious work experience. At the beginning of the process, the experiment and data always can't meet our requirement. Thus, students have to analyze the craft process, conditions, impact factors and the theory. This can help to train and improve students' ability of comprehensive analyzing and solving problems, namely, it can teach students what to do and how to do. The procedure from fundamental science to technology science is practice, perceptual understanding, conceptual understanding, practice, theoretical science, applied science and engineering technology. It is a circulation from practice to perceptual to conceptual and then back to practice. Teachers should lead students to analyze the experiment, conditions, inner connection and the changing regulations on the basis of experimental records. Next, students should explain the phenomenon and changing regulations of the data by using theoretical knowledge, in order to find out the reasonable and unreasonable part, which can become the guidance on redesigning the experiment to get better conditions and parameter. At last, students can effectively cultivate their operation ability and knowledge utilized ability through conclusions.

People always release their whole power first, and then treat it like a target. But it must get through a catabolic form before it becomes possible. The catabolic form is a process which can reflect students' own innovative ability. The guidance towards to students is a process which can find out students' potential abilities and improve their judgment, imagination and instinct on objects. On one hand, students should have risk awareness and adventure spirit, and dare to try and create. On the other hand, students should also be rigorous and learn from the mistakes in time. On that way, the comprehensive quality of student will be improved.

Confirm the significance of the project. The end of the graduation project means the end of the thesis. It reflects the attitude and ability of students. After finishing the experiments, the next task is to deal with the data, and characterize the results according to the conditions and data. Situations of recent years reflect that most students don't know how to organize and settle the data because they are lack of guidance and practice. But it doesn't mean that teachers should help them to write the paper. They can lead them to know better about the structure of the thesis and organize it. They can give the outline, contents, key points, experimental conditions and impact factors to students and teach them how to explain the phenomenon by using theoretical knowledge. This can help students perform better on the thesis and cultivate their ability.

\section{The comment of graduation project is a reflection of problems}

The oral defense is the reflection of students' comprehensive ability. It can show us that how students utilize the materials, organize the thesis, operate during the experimental process, combine the theoretical with actual data, analyze and state. We can't just focus on the conclusion and answer during the oral defense, we should notice the questions, especially the process of finding questions, conditions and factors. Marx told us that question is the slogan of an era. A question proposed at the era is reasonable because of its legitimate contents. And the common difficulty among them is not the answer but the question. Just like an algebraic equation, it will be solved out as long as it is accurate enough. Therefore, as long as it is a practical question, the answer is always there. That means the question is more meaningful than the answer. In fact, the proposal of a question needs both courage and wisdom. One important characteristics of the creator is that he dares to and is good at discovering and proposing questions. Whether one can discover and propose question reflects the ability of initiative and creative to a certain degree. If we want to examine whether the goal of cultivating the comprehensive ability of students has reached or not, we can focus on the students' understanding degree to a question which is theoretical and practical or the ability of finding out the solution to a question when students are guided by teachers. 


\section{Responsibility of teachers}

The centre of education is students, a few points are very important as follow. First, we must respect students' interest. Second, respect students' emotion. Teachers should think on students' side, and it can help to promote students' positivity. Third, respect their ambition and direction. The goal of education is students' future. Allow student to select their topic, even it is not related to their major. The common goal of college teachers is to develop students' potential. Fourth, respect students' willing, choose and judgment. We should not mold students but to help them to reach their goals. Fifth, respect all students, no matter bad or good. Every student has his own advantage, and teacher's responsibility is to discover their ability. The motivation of college and teacher is to cultivate a student who can contribute to the society.

\section{References}

[1] Zhou Shi-peng. 2001 Knowledge economy after-development human creation J. B1 philosophical theory. 1 143-147

[2] Ren Wei and Wu Guishu. 2012 Study on educational situation and cooperation pattern in cooperation of industry, university and research J. Higher education. 628145.

[3] LI Sheng and MuhetaerZhari. 2012 Strengthening Practice to Improve the Mode of Cultivating Applied Talents J. CHINESE GEOLOGICAL EDUCATION. 1 104-105

[4] Liu Qingquan and Xiao Qiuguo. 2012 Thinking about characteristic specialty construction of "material chemistry" J. Theory and Practice of Contemporary Education. 4 103-105.

[5] Yang Guangjin and Jiang Tao. 2012 Study on pattern and efficiency of construction of training base through cooperation of college and enterprise J. China academic journal electronic publishing house. 2 12 13.

[6] M 1979 Die Marx Engels Gesamtausgabe Pelple's Publishing House vol.40 p123.

[7] M 1979 Die Marx Engels Gesamtausgabe Pelple's Publishing House vol.42 p289. 